\title{
Irrigators' Association and Farm Productivity : A Comparative Study of Two Philippne Irrigation Systems
}

\author{
Michael Gragasin*, Atsushi Maruyama*, Esther Marciano $^{\dagger}$, \\ Masako Fujiie ${ }^{\ddagger}$ and Masao Kikuchi*
}

\begin{abstract}
The effect of irrigators' associations on the productivity of rice farming is examined, using data obtained from two irrigation systems in the Philippines, one with an irrigators' association and the other without. The estimation of the production function confirms that the irrigators' association is not effective in reducing inequitable water distribution among the different locations in the system, and fails to demonstrate that it provides any significant advantages over the system with no irrigators' association in terms of productivity. However, we found that the mean level of farmers' technical efficiency is higher and the variation in farmers' technical efficiency is smaller in the system with the irrigators' association than in the system without an irrigators' association, suggesting that the irrigators' association is effective in ensuring the efficient and equitable distribution of water among farmers within each location in the system.
\end{abstract}

Key words : frontier production function, rice production, technical efficiency, water users.

\section{Introduction}

In developing countries, the last two decades have witnessed a strong drive to involve water-users in the operation and management of irrigation systems managed hitherto by state agencies, and a further drive to transfer the responsibility of managing the irrigation systems from the agencies to the groups of water-users (Uphoff [31], Ostrom [25], Vermillion [33]). Underlying this trend has been the recognition that the participation of water-users in the management of irrigation systems is a prerequisite for sustaining the performance of these systems. Most

\footnotetext{
* Chiba University

${ }^{\dagger}$ The International Rice Research Institute

‡Takushoku University

This paper is an output of the IRRI-Japan Shuttle Project. The authors are grateful to K. Kalirajan, K. Kajisa, N. Fuwa, and two anonymous referees of this journal for their invaluable comments on an earlier version of this paper.
}

irrigation systems were constructed during the last few decades of the green revolution, but have been on the verge of rapid deterioration owing to poor operation and maintenance (Kikuchi et al. [16]).

The new paradigm favoring a participatory approach takes for granted that if groups of water-users, or irrigators' associations, are established, they will have a positive impact on the performance of irrigation systems, both directly through improving the quality of system operation to bring about a more equitable water distribution among water users, and indirectly through improving the quality of system maintenance. As a result, the productivity of irrigated agriculture is expected to be higher in irrigation systems with farmer participation than in systems without such participation.

However, in spite of the enthusiasm of the advocates of this new paradigm, the results of participatory irrigation management thus far have been mixed (Kloezen et al. [19], Uphoff and Wijayaratna [32], Vermillion 
[33]). Definitive evidence of a positive link between the participatory approach and improved performance of irrigation systems remains to be found. In particular, as Vermillion [33] points out, there have been few studies that examine the impacts of the new paradigm on the productivity of irrigated agriculture. This is largely due to the difficulty of isolating the impact of the new paradigm from numerous other factors that affect the productivity of irrigated agriculture. The rapid deterioration of irrigation systems in developing countries because of inadequate management makes it an urgent need to understand the conditions under which the participatory approach results in better management, and hence better performance of irrigation systems.

The purpose of this paper is to fill this gap in the research by examining whether the existence of irrigators' associations actually enhances the productivity of rice production, based on data collected in two irrigation systems in the Philippines, one with irrigators' associations and the other without. We attempt to estimate the productivity performance of irrigators' association by estimating the stochastic frontier production function for rice production in the two sample systems.

We focus on irrigation systems in the Philippines, because the Philippines has been a forerunner in adopting the new paradigm of participatory irrigation management. As a national policy, the National Irrigation Administration (NIA) ${ }^{1)}$ has been attempting to create irrigators' associations, and to hand them responsibility for the operation and maintenance of irrigation systems (Bagadion [2]). Because of these pioneering attempts, many proponents of the participatory approach regard the Philippines as a model country (Korten and Siy [20], Ostrom [25], Small and Carruthers [28]). As in other countries, the attempt in the Philippines to adopt the new approach has produced a wide spectrum of results, ranging from success (Svendsen [29], Wijayaratna and Vermillion [34]) to failure (Kikuchi et al. [16], Oorthuizen and Kloezen [24]). Under these circumstances, the irrigation sector of the Philippines provides researchers in this field with good testing grounds.
In the following section, we first outline the irrigation sector in the Philippines and our sample irrigation systems. The third section will be devoted to an overview of rice farming in the sample systems. We then present in the fourth section the estimation results of stochastic frontier production function and examine how productivity in rice farming differs between the irrigation systems with and without irrigators' associations. The final section gives concluding remarks.

\section{Sample Irrigation Systems}

For this study, we selected two irrigation systems situated in Region 4, one of 14 administrative regions of NIA. Before outlining the sample systems and rice farming there, let us look briefly into the irrigation sector of the Philippines and Region 4, and observe the status of irrigators' associations (IAs) in the sector.

\section{1) The Philippine irrigation sector and} irrigators' associations

Rice being the staple food, the irrigation sector of the Philippines has been a vital sector politically as well as economically. As of 2003 , the total irrigated paddy fields of 1.2 million ha, consisting of 0.7 million ha under national irrigation systems (NISs) and 0.5 million ha under communal irrigation systems $(\mathrm{CISs})^{2)}$, account for $70 \%$ of total area planted to rice and $80 \%$ of total rice production of the country (NIA [23], BAS [6]). The total irrigated area in 1952 was 0.4 million ha, 0.1 million ha under NISs and 0.3 million ha under CISs (Kikuchi et al. [15]). During the last half century, the total irrigated area increased by as much as three times. In particular, the increase in irrigated area under NISs has been enormous, nearly $50 \%$ of which was concentrated in the decade starting from the so-called "world food crisis" in 1973-74. It is in these NISs that the quality deterioration has been serious since the mid1980 s when the world rice price began to decline dramatically due largely to the success of the "green-revolution" in the Asian tropics (Kikuchi et al. [17], Masicat et al. [21]). ${ }^{3)}$

In 1984, the NIA adopted participatory irrigation management (PIM) for NISs as a state policy and started to organize IAs to which the maintenance responsibility of irrigation 
Table 1. The status of irrigators' associations (IAs) in national irrigation systems (NISs), 2000

\begin{tabular}{lcccccc}
\hline & \multicolumn{2}{c}{ Number } & & \multicolumn{2}{c}{ Area covered } \\
\cline { 2 - 3 } \cline { 5 - 6 } & & $\%$ & & $(1000$ ha $)$ & $\%$ \\
\hline IAs organized & 2,079 & 100 & & $\left.656^{\mathrm{a}}\right)$ & 100 \\
& & & & & \\
IAs with O \& M contractb) & 1,654 & 80 & & 527 & 80 \\
$\quad$ Functional & 1,029 & 50 & & na & \\
Not functional & 625 & 30 & & na & \\
\hline
\end{tabular}

a) About $98 \%$ of the entire service area of NISs. b) IAs that sign maintenance contracts with NIA. Whether functional or not is rated by NIA regional offices. Source : Mejia [22].

systems was to be transferred.4) By the year 2000, more than two thousand IAs had been established, which covered $98 \%$ of the total command areas of 190 NISs (Table 1). However, not all IAs are functional. The responsibility of maintaining a part of the tertiary system in NISs is transferred to an IA when it signs a maintenance contract with the NIA. ${ }^{5)}$ Of the entire IAs established, $80 \%$ have such a contract. It is reported that $60 \%$ of IAs with the contract are functional, and the remaining $40 \%$ are not. This leaves only $50 \%$ of the entire IAs that are functional.

Region 4, also called Southern Tagalog, covers 10 provinces, including Laguna, Batangas, Cavite, Quezon, Occidental Mindoro and Oriental Mindoro as major provinces having NISs. There are 45 NISs in Region 4 , the largest number among NIA's 14 regions, but reflecting the hilly and mountainous topography of these provinces, the size of the systems in terms of service area is relatively small, on average 1,200 ha. ${ }^{6)}$ A survey we conducted in 1998 covering $50 \%$ of 90 IAs in this region reveals that the performance of IAs differs, significantly across associations (Table 2). ${ }^{7)}$ There are well-functioning IAs on one side, while there are non-functioning ones on the other side. It is worth noting that the percentage of IAs the performance of which is above average is about $60 \%$. This is similar to the percentage of functional IAs for the country at large.

2) Sample systems and sample farmers

The first system, with irrigators' associations (IAs), is a national irrigation system in Oriental Mindoro (referred to as the Mindoro System or Mindoro in short) with the com- mand area of 2, 800 ha, which has been operated and managed by the NIA since its construction in 1960. Mindoro is the seventh largest island in the Philippines, and is situated off the main island of Luzon at its southern part. In the Mindoro System, an IA was formed in 1983 covering the entire service area which is divided into three divisions. However, the size of the association was found to be too large to be functional. Upon request from farmers, in 1993, the IA was divided into three IAs, one for each division, and since then these three IAs have undertaken group maintenance activities and water rotation between divisions and laterals. It is said that the IA of Division 3 is particularly well organized as both rotation between the laterals and between the upper and lower reaches within the laterals are well implemented.8)

The second system, without an IA, is a national irrigation system in Cavite (referred to as the Cavite System or Cavite in short) with the command area of 610 ha, operated and maintained by NIA. Cavite is a province adjacent to Metro Manila, and the command area of this system is situated $30 \mathrm{~km}$ southwest of the capital city. This system is one of $19 \mathrm{sub}-$ systems of the 13, 500 ha Cavite Friar Land Irrigation System, the construction of which dates back to the Spanish period. The NIA has been trying to form an IA in this system since the 1980s, but so far has had no success. An initial IA was formed in 1986 under the NIA's guidance in a "top-down" mode, but it was not active, existing only on the NIA's records. In 1996, a Water Master (a rank of a field-level NIA officer, above ditch 
Table 2. Distribution of IAs by performance ranking class, Region 4

\begin{tabular}{crr}
\hline Performance ranking & No. of IA & $\%$ \\
\hline 1 (top) & 13 & 28 \\
2 & 8 & 17 \\
3 & 4 & 9 \\
4 & 3 & 7 \\
\hline 5 & 2 & 4 \\
6 & 1 & 2 \\
7 & 6 & 13 \\
8 (bottom) & 9 & 20 \\
\hline Total & 46 & 100 \\
\hline
\end{tabular}

Source: Based on our survey conducted in 1998. For details, see Fujiie et al. [11].

tender) who was newly assigned to this system attempted to activate the IA and the irrigation management transfer was implemented at once. But, the IA's system management failed within a year, mainly because of poor leadership. The management responsibility was returned to the NIA in 1997, and the IA has been defunct since. In this system, which is de facto without an IA, two kinds of water rotation, between the two main canals and between the upper and lower reaches along the two canals, are implemented by the NIA. It is reported that the between-lateral rotation has been enforced reasonably well, but the within-lateral rotation has not been so successful due to opportunistic behavior by farmers.

We conducted a field survey in these irrigation systems in August-September 2000 to collect data on rice production. In the Mindoro System, we drew farm samples from a lateral with 350 ha of service area in Division 3 , the tail-end division in the system. In both systems, farmers cultivating in the upper reach, the middle reach and the lower reach were chosen randomly to be interviewed. The two sample systems are both rice systems, as rice is the major crop grown, with few other diversified crops. The cropping seasons for which data were obtained are the 1999 wet season and the 1999/2000 dry season. ${ }^{9)}$

The number of sample farmers and their basic characteristics are summarized in Table 3. On average, sample rice farmers in the two systems share similar characteristics in terms of farm size, family size, age and educational attainment of operators, and land tenure status. The difference in the total household income is not very large, though income from rice farming in Mindoro is twice as high as in Cavite. The market wage rates are significantly higher in Cavite than in Mindoro, reflecting Cavite's proximity to MetroManila. The impact of urbanization is more distinct in Cavite, and rice farming there exhibits more characteristics of part-time farming. In spite of its isolated location on a small island off the main island of Luzon, non-farm income in Mindoro is as large as in Cavite. This is mainly because there is no significant difference between Cavite and Mindoro in the amount of remittances from abroad.

We did not conduct any water measurement in the sample systems. Judging from farmers' responses as to water availability in the dry season, both systems apparently suffer from an unequal water distribution among locations, which is a typical problem of gravity irrigation systems. The percentage of farmers who answered that a sufficient amount of water was available in the dry season is slightly higher for all the locations in Mindoro than in Cavite, but the differences are marginal. A significant difference between the two systems is found in the percentage of farmers who paid irrigation fees. Farmers' fee payment records are far better in Cavite than in Mindoro. In Mindoro, the rate of fee payment decreases sharply from the upper reach to the lower reach, as is the case for the rate of water sufficiency. This seems to represent a typical case in which the willingness to pay irrigation fee depends on water availability. The same trend is observed in Cavite, but the differences between the locations are small compared to the differences in the rate of water sufficiency. ${ }^{10)}$

\section{3) Rice production in the sample systems}

Let us first observe rice yield per hectare in the sample systems by season and by location in the systems (Table 4). We note first that there is no yield difference between wet and dry seasons, as seasonal yield difference is not statistically significant for any of the locations in either system. In the remainder of this section, therefore, we make no distinction between the two seasons. 
Table 3. Farm characteristics in the sample systems, as of $2000^{\text {a) }}$

\begin{tabular}{|c|c|c|}
\hline & $\begin{array}{l}\text { Mindoro } \\
\text { System }\end{array}$ & $\begin{array}{l}\text { Cavite } \\
\text { System }\end{array}$ \\
\hline \multicolumn{3}{|l|}{ Number of farmers interviewed } \\
\hline Upper reach & 15 & 27 \\
\hline Middle reach & 19 & 13 \\
\hline Lower reach & 28 & 32 \\
\hline Total & 62 & 72 \\
\hline Farm size (ha) & 1. $7(1.4)$ & $1.3(0.6)$ \\
\hline Family size (No. ) & $6.7(2.3)$ & $7.5(2.9)$ \\
\hline Age of operators & $49.4(9.8)$ & 54. $2(13.4)$ \\
\hline $\begin{array}{l}\text { Educational level of operators } \\
\quad \text { (years of schooling) }\end{array}$ & 7. $2(2.9)$ & $6.1(3.5)$ \\
\hline \multicolumn{3}{|c|}{$\%$ share of farm workers in household labor force } \\
\hline Household Income (1999-2000 ; Peso 000/yr) & $19(9)$ & $23(13)$ \\
\hline Rice & $49(47)$ & $23(17)$ \\
\hline Non-rice farming & $10(16)$ & $17(24)$ \\
\hline Non-farm & $42(54)$ & $44(54)$ \\
\hline Total & $101(78)$ & $84(67)$ \\
\hline \multicolumn{3}{|l|}{ Wage (Peso/day) } \\
\hline Agriculture & 120 & 150 \\
\hline Construction & $120-150$ & $180-200$ \\
\hline \multicolumn{3}{|l|}{ Tenure Status $(\%)$} \\
\hline Owner & 48 & 36 \\
\hline Leasehold & 24 & 46 \\
\hline Share-tenancy & 27 & 12 \\
\hline Sub-tenancy & 1 & 5 \\
\hline \multicolumn{3}{|c|}{$\%$ of farmers with sufficient water in dry season } \\
\hline Upper reach & 93 & 85 \\
\hline Middle reach & 74 & 69 \\
\hline Lower reach & 37 & 26 \\
\hline Total & 62 & 58 \\
\hline \multicolumn{3}{|c|}{$\%$ of farmers who paid irrigation fees in $1999-2000$} \\
\hline Upper reach & 68 & 81 \\
\hline Middle reach & 50 & 80 \\
\hline Lower reach & 47 & 71 \\
\hline Total & 53 & 77 \\
\hline
\end{tabular}

a) Figures in parenthesis are standard deviation.

Source : Our survey.

For the systems as a whole, average rice yield in the Mindoro System is $3.9 \mathrm{t}$ per hectare, while it is $3.3 \mathrm{t}$ per hectare in the Cavite System. The inter-system yield difference is statistically significant at the ten percent significance level or higher for all locations except for the wet and dry seasons in the lower reach. Such yield differences are to be expected in irrigation systems with and without IAs.

A problem inherent in gravity irrigation systems is the difficulty of distributing irrigation water equitably among farmers. It is virtually a law that farmers at the head-end of the system have an advantage and are able to use water more lavishly than farmers at the tail-end, and that when water is scarce the tail-enders suffer more seriously than 
Table 4. Average rice yield per hectare by season, location and system, 1999 wet and $1999 / 2000$ dry $^{a}$

\begin{tabular}{|c|c|c|c|c|c|c|c|c|}
\hline \multirow[b]{2}{*}{ Location } & \multirow[b]{2}{*}{ Season } & \multicolumn{3}{|c|}{ Mindoro System } & \multicolumn{3}{|c|}{ Cavite System } & \multirow{2}{*}{$\begin{array}{l}\text { Difference } \\
\text { between } \\
\text { systems } \\
(\mathrm{kg} / \mathrm{ha})\end{array}$} \\
\hline & & $\begin{array}{l}\text { Mean } \\
(\mathrm{kg} / \mathrm{ha})\end{array}$ & $\begin{array}{l}\text { C. V. } \\
(\%)\end{array}$ & $\begin{array}{l}\text { No. of } \\
\text { obser- } \\
\text { vations }\end{array}$ & $\begin{array}{l}\text { Mean } \\
(\mathrm{kg} / \mathrm{ha})\end{array}$ & $\begin{array}{l}\text { C. V. } \\
\text { (\%) }\end{array}$ & $\begin{array}{l}\text { No. of } \\
\text { obser- } \\
\text { vations }\end{array}$ & \\
\hline \multirow[t]{3}{*}{ Upper } & Wet & 4662 & 10 & (15) & 3658 & 31 & (27) & $1004^{* * *}$ \\
\hline & Dry & 4568 & 16 & (15) & 3680 & 33 & (26) & $888^{* *}$ \\
\hline & Total (A) & 4615 & 13 & (30) & 3669 & 32 & (53) & $947^{* * *}$ \\
\hline \multirow[t]{3}{*}{ Middle } & Wet & 4264 & 24 & (19) & 3415 & 19 & (13) & $849^{* *}$ \\
\hline & Dry & 4156 & 23 & (19) & 3310 & 23 & (13) & $846^{* *}$ \\
\hline & Total (B) & 4210 & 24 & (38) & 3362 & 20 & (26) & $847^{* * *}$ \\
\hline \multirow[t]{3}{*}{ Lower } & Wet & 3323 & 34 & (28) & 2981 & 31 & $(32)$ & 342 \\
\hline & Dry & 3374 & 31 & (27) & 3062 & 34 & (27) & 311 \\
\hline & Total (C) & 3348 & 32 & (55) & 3018 & 32 & (59) & $330^{*}$ \\
\hline \multirow[t]{3}{*}{ Total } & Wet & 3935 & 29 & (62) & 3313 & 31 & (72) & $622^{* * *}$ \\
\hline & Dry & 3911 & 27 & (61) & 3355 & 32 & (66) & $557^{* * *}$ \\
\hline & Total & 3923 & 28 & (123) & 3333 & 31 & (138) & $590 * * *$ \\
\hline Difference & $(A-B)$ & $405^{*}$ & & & 306 & & & \\
\hline between & $(B-C)$ & $862^{* * *}$ & & & 344 & & & \\
\hline locations & $(A-C)$ & $1267^{* * *}$ & & & $650^{* * *}$ & & & \\
\hline
\end{tabular}

a)C. V. stands for coefficient of variation. Differences marked with***, ${ }^{* *}$ and ${ }^{*}$ are statistically significant at $1 \%, 5 \%$ and $10 \%$, respectively, in the $t$-test for mean difference. The numbers of observations in the dry season are fewer than in the wet season because some farmers did not plant rice in the dry season.

Source : Our survey.

head-enders (Chambers, [7]). The result is a higher yield at the head-end than at the tailend. This is exactly the case in the sample systems ; farmers in the upper reach attain significantly higher yield than those in the lower reach in both systems. The yield differences between upstream and downstream are, however, smaller in Cavite than in Mindoro. In Cavite, the yield difference is statistically significant only between upper and lower reaches, while in Mindoro it is significant not only between upper and lower reaches but also between upper and middle reaches and between middle and lower reaches. One may expect that irrigation systems with IAs attain more equitable water distribution within their systems through implementing water rotation and other measures that improve system performance. If so, ceteris paribus, yield differences between upstream and downstream are expected to be smaller in irrigation systems with IAs than in those without. At a glance, our sample systems do not satisfy this expectation.
More equitable water distribution because of a well-functioning IA may reveal a positive impact in terms of smaller variation in rice yield per hectare within an irrigation system. Table 4 shows that the yield variation for the system as a whole, as measured by the coefficient of variation, is slightly larger in Cavite than in Mindoro. It is also interesting to observe that the variation was relatively large in the dry season in Cavite. However, more distinct is the observation that the yield variation becomes larger as one moves from the upper to the lower reaches in Mindoro. In contrast, the same degree of yield variation is observed for the upper and the lower reaches in Cavite. Simple statistical analyses of rice yield per hectare thus deny any easy conclusion about the impacts of IAs on productivity in rice production.

Needless to say, rice yield per hectare depends not only on IA activities but even more heavily on various other factors, such as the levels of production inputs and farmers' technology. Table 5 summarizes the structure of 
Table 5. Factor payments and factor shares of rice production per hectare, Mindoro and Cavite, wet and dry season average, 1999/2000

\begin{tabular}{|c|c|c|c|c|c|c|c|c|}
\hline \multirow{2}{*}{ Factors } & \multicolumn{4}{|c|}{ Factor payments $(\mathrm{kg} / \mathrm{ha})^{\mathrm{a})}$} & \multicolumn{4}{|c|}{ Factor shares $(\%)$} \\
\hline & Upper & Middle & Lower & Total & Upper & Middle & Lower & Total \\
\hline \multicolumn{9}{|l|}{ Mindoro System : } \\
\hline Rice output & 4,615 & 4,210 & 3,348 & 3,923 & 100 & 100 & 100 & 100 \\
\hline Current inputs & 819 & 914 & 717 & 803 & 18 & 22 & 21 & 20 \\
\hline Capital & 434 & 417 & 361 & 394 & 9 & 10 & 11 & 10 \\
\hline Labor & 1,231 & 1,214 & 992 & 1,114 & 27 & 29 & 30 & 28 \\
\hline Return to land $\mathrm{d}^{\mathrm{b})}$ & 2,131 & 1,665 & 1,278 & 1,612 & 46 & 40 & 38 & 41 \\
\hline \multicolumn{9}{|l|}{ Cavite System : } \\
\hline Rice output & 3,669 & 3,362 & 3,018 & 3,333 & 100 & 100 & 100 & 100 \\
\hline Current inputs & 649 & 587 & 597 & 612 & 18 & 17 & 20 & 18 \\
\hline Capital & 608 & 528 & 548 & 563 & 17 & 16 & 18 & 17 \\
\hline Labor & 1,705 & 1,480 & 1,312 & 1,473 & 46 & 44 & 43 & 44 \\
\hline Return to land ${ }^{\mathrm{b})}$ & 707 & 767 & 561 & 685 & 19 & 23 & 19 & 21 \\
\hline
\end{tabular}

a) Factor payments converted to paddy equivalents by the factor-output price ratios. b) Estimated as residual (gross output-non-land costs), including profit.

Source : Our survey.

rice production in the sample systems in terms of factor payments and factor shares. Production inputs are grouped into four categories : current inputs, such as seeds, fertilizers and chemicals ; fixed capital services, such as carabaos (water buffalos) and tractors used for land preparation; labor ; and land. It should be noted that all production inputs, both purchased and self-supplied are accounted for. Self-supplied inputs, such as family labor, are imputed at their market prices.

As expected, factor payments per hectare in each system tend to become lower as one progresses from the upper reach to the lower reach in the two systems. However, some cases do not follow this trend. For example, the intensity of current inputs is highest in the middle reach in the Mindoro System. In the Cavite System, such a reversal is found for current inputs and capital between the middle reach and the lower reach. Between the two systems, the intensity of current inputs is higher in Mindoro than in Cavite, but the opposite is the case for capital and labor. The higher intensity of capital in Cavite may be understood as a result of attempts by farmers, who face a higher wage rate than in Mindoro (Table 3), to substitute labor for capital. In fact, referring to the labor input per hectare in Table 6, the capital-labor ratio is higher in Cavite than in Mindoro. In the context of this study, it is interesting to note that the labor input per hectare in the Cavite System without the IA is larger than in the Mindoro System with the IA, mainly because of the need of farmers in Cavite to use more labor for irrigation control.

These differences in the non-land costs between the two systems lead to the most distinct inter-system difference in the return to land; it is far larger in Mindoro than in Cavite (Table 5). As a result, the factor shares in rice production differ significantly between the two systems. In Cavite, the share of labor for the system as a whole is as high as $44 \%$, followed by the share of land at $21 \%$. In contrast, the share of land for the system as a whole is as high as $41 \%$ in Mindoro, followed by the share of labor at $28 \%$. It should be remarked that the intra-system differences in factor shares are not as distinct as the inter-system differences. This leads to the following question: does the higher rice output with the lower non-land costs indicate the higher productivity in rice production in the Mindoro System as compared to the Cavite System? And if so, is it due to the existence of the IA in the Mindoro System? 
Table 6. Labor use (person-days) per hectare for rice production, Mindoro and Cavite, wet and dry season average, 1999/2000

\begin{tabular}{|c|c|c|c|c|c|c|c|c|}
\hline & \multicolumn{4}{|c|}{ Mindoro System } & \multicolumn{4}{|c|}{ Cavite System } \\
\hline & Upper & Middle & Lower & Total & Upper & Middle & Lower & Total \\
\hline Irrigation control & 2.6 & 2.1 & 3.2 & 2.7 & 7.8 & 7.6 & 6.8 & 7. 1 \\
\hline Others & 58.8 & 65.2 & 50.9 & 57.7 & 58.9 & 56.3 & 55.2 & 56.4 \\
\hline Totala) & $\begin{array}{c}61.4 \\
(19.8)\end{array}$ & $\begin{array}{c}67.3 \\
(17.4)\end{array}$ & $\begin{array}{c}54.1 \\
(11.5)\end{array}$ & $\begin{array}{c}60.4 \\
(16.3)\end{array}$ & $\begin{array}{c}66.7 \\
(16.1)\end{array}$ & $\begin{array}{c}63.9 \\
(13.2)\end{array}$ & $\begin{array}{c}62.0 \\
(18.2)\end{array}$ & $\begin{array}{c}63.6 \\
(16.7)\end{array}$ \\
\hline
\end{tabular}

a) Figures in parenthesis are standard deviation.

Source : Our survey.

\section{Estimation of the Rice Production Function}

The above overview of rice farming in the two sample systems reveals that rice yield per hectare differs according to the locations in each system, and that the production structure observed in terms of factor shares is significantly different between the two systems. However, it provides no answer to the question as to how far the existence of the IA in one of the irrigation systems affects the productivity of rice production. In this section, we try to obtain some clues to answer this question through estimating the frontier production function by which we analyze the level and variance of technical efficiency of individual rice farmers in the two systems as well as differences in the structure of rice farming between the systems.

\section{1) Theoretical model}

Since the concept was introduced by Farrell [10], various frontier production function (FPF) models have been developed. An FPF represents the maximum level of output that is possible to produce with a given level of production inputs, and the gap between the FPF and a farmer's actual level of output is called technical inefficiency or productive inefficiency. The FPF model is classified as a deterministic model or a stochastic model according to the assumption made for the disturbance terms. It can be further classified into three categories in terms of the way noninput exogenous variables $(\mathbf{Z})$, such as characteristics of individual farmers, are incorporated in the analysis of technical efficiency (Simar et al. [27]).

The first category treats $\mathbf{Z}$ as influencing the structure of production possibilities di- rectly (Pitt and Lee [26]). By contrast, the second category treats $\mathbf{Z}$ as influencing the degree of technical inefficiency, and applies a two-step estimation : the first step estimates the FPF using input variables and the second step explains production inefficiency using $\mathbf{Z}$ (Kalirajan [14]). There are drawbacks to these approaches : the first category gives no explanation of efficiency variation, while in the second category, the exclusion of $\mathbf{Z}$ in the first step possibly causes the omitted variable problem, resulting in the biased estimation of the coefficients of input variables and hence of technical inefficiency. The third category, which also treats $\mathbf{Z}$ as influencing the degree of technical inefficiency, adopts a onestep estimation to overcome the omitted variable problem (Simar et al. [27], Battese and Coelli [5]).

Our primary purpose in estimating FPF is to measure farmers' technical inefficiency while controlling as many exogenous variables $(\mathbf{Z})$ as possible except IA-related variables that are difficult to measure. Hence, it is legitimate for us to adopt the first category in this study. It should be noted that adopting the model developed by Battese and Coelli [5], which belongs to the third category, does not alter the basic conclusions. In regard to the first classification, it is preferable to adopt a stochastic FPF model, since it more properly takes measurement errors and other statistical noises into account. In this study, we adopt a stochastic frontier model pioneered by Aigner et al. [1] and developed into a standard method by Greene [13; pp. 501-505].

Our stochastic frontier production function can be written as follows : 


$$
\log \mathrm{y}_{i}=f\left(\mathbf{X}_{i}, \mathbf{Z}_{i}, \boldsymbol{\beta}, \boldsymbol{\gamma}\right)+\mathrm{v}_{i}-\mathrm{u}_{i}
$$

where $\mathrm{y}_{i}$ is the output of the $i$-th farmer ; $\mathbf{X}_{i}$ is a $1 \times \mathrm{k}$ vector of input variables in log form of the $i$-th farmer ; $\mathbf{Z}_{i}$ is a $1 \times \mathrm{m}$ vector of non-input exogenous variables of the $i$-th farmer ; $\boldsymbol{\beta}$ is a $1 \times \mathrm{k}$ vector of unknown parameters ; $\boldsymbol{\gamma}$ is a $1 \times \mathrm{m}$ vector of unknown parameters; $\mathrm{v}_{i}$ is the random error that captures statistical noise, measurement error, and exogenous shocks beyond the control of farmers, assumed to be independently and identically normally distributed $N\left(0, \sigma_{v}{ }^{2}\right)$; and $\mathrm{u}_{i}$ is a non-negative random variable that represents the departure from the frontier due to technical inefficiency of individual farmers. The technical efficiency of the $i$-th farmer, $\mathrm{TE}_{i}$, is defined as $\exp \left(-\mathrm{u}_{i}\right)$. If the term, $\mathrm{v}_{i}-\mathrm{u}_{i}$, is replaced by $\mathrm{e}_{i}$, which is the statistical noise of $N\left(0, \sigma_{\mathrm{e}}^{2}\right)$, Equation (1) becomes an ordinary average production function.

Following Greene [13], let us assume two alternative distributions for $\mathrm{u}_{i}$ : half-normal and exponential. The density function for the half-normal model is

$$
\begin{aligned}
\log h\left(\varepsilon_{i} \mid \boldsymbol{\beta}, \boldsymbol{\gamma}, \lambda, \sigma\right)= & {\left[-(1 / 2) \log \sigma^{2}\right.} \\
& +(1 / 2) \log (2 \pi) \\
& -(1 / 2)\left(\varepsilon_{i} / \boldsymbol{\sigma}\right)^{2} \\
& \left.+\log \Phi\left(-\varepsilon_{i} \lambda / \boldsymbol{\sigma}\right)\right]
\end{aligned}
$$

where $\varepsilon_{i}=\mathrm{v}_{i}-\mathrm{u}_{i}, \quad \lambda=\sigma_{u} / \sigma_{v}, \quad \sigma=\left(\sigma_{u}^{2}+\sigma_{v}^{2}\right)^{1 / 2}$, and $\Phi(\cdot)=$ the cumulative function of the standard normal distribution. The disturbance, $\varepsilon_{i}$, has a nonzero mean, $\mathrm{E}\left(\varepsilon_{i}\right)=-\sigma_{u}(2 /$ $\pi)^{1 / 2}$.

The density function for the exponential model is

$$
\begin{aligned}
\log h & \left(\varepsilon_{i} \mid \boldsymbol{\beta}, \boldsymbol{\gamma}, \theta, \sigma_{v}\right) \\
= & {\left[\log \theta+(1 / 2) \theta^{2} \sigma_{v}^{2}+\theta \varepsilon_{I}\right.} \\
& \left.+\log \Phi\left(-\varepsilon_{i} / \sigma_{v}-\theta \sigma_{v}\right)\right]
\end{aligned}
$$

where $\theta=-1 / \mathrm{E}\left(\varepsilon_{i}\right)$. The model parameters are estimated by the maximum-likelihood method using these functions.

The estimated technical inefficiency of the $i$-th farmer is calculated using the following equations :

$$
\begin{aligned}
& E\left(\mathrm{u}_{i} \mid \varepsilon_{\mathrm{i}}\right) \\
& \quad=(\sigma \lambda) /\left(1+\lambda^{2}\right)[\phi(\mathrm{s}) /(1-\Phi(\mathrm{s}))-\mathrm{s}]
\end{aligned}
$$

for the half-normal model, and

$$
E\left(\mathrm{u}_{i} \mid \varepsilon_{i}\right)=\mathrm{s}+\sigma_{v}\left[\phi\left(\mathrm{s} / \sigma_{v}\right) / \Phi\left(\mathrm{s} / \sigma_{v}\right)\right]
$$

for the exponential model, where $s=\varepsilon \lambda / \sigma$ and $\phi(\cdot)$ is the probability density function of the standard normal distribution.

\section{2) Regression model}

Our regression model for the stochastic FPF in Cobb-Douglas form is given as follows :

$$
\begin{aligned}
\log \text { Yield }_{i}= & \beta_{0}+\beta_{1} \log \text { Land }_{i}+\beta_{2} \log \text { Current }_{i} \\
& +\beta_{3} \log \text { Labor }_{i}+\beta_{4} \log \text { Capital }_{i} \\
& +\gamma_{1} \text { Location }_{i}+\gamma_{2} \text { Age }_{i} \\
& +\gamma_{3} \text { Education }_{i}+\gamma_{4} \text { Land tenure }_{i} \\
& +\gamma_{5} \text { Season }_{i}+\gamma_{6} \text { Rice ratio }_{i} \\
& +\gamma_{7} \text { Farm-worker ratio }_{i} \\
& +\mathrm{v}_{i}-\mathrm{u}_{i}
\end{aligned}
$$

where Yield is rice output $(\mathrm{kg})$; Land is area planted to rice (ha) ; Current is the sum of purchased and/or self-supplied current inputs (peso) ; Labor is labor inputs (personhours) ; Capital is the sum of paid out and/ or imputed rentals of carabaos and tractors (peso) ;11) Location is a variable denoting the location of farmers' rice fields in the irrigation system (upper reach $=1$, middle reach $=2$ and lower reach=3); Age is the age of the farm operator ; Education is the educational attainment of the farm operator (years of schooling) ; Land-tenure is a dummy variable representing the tenure status of farmers (owner operator $=1$, otherwise $=0$ ) ; Season is a dummy variable representing the cropping season (Dry $=1$; Wet $=0)$; Rice ratio is the ratio of the income from rice farming to the total household income ; and Farm-worker ratio is the ratio of the number of farm workers to the total number of workers. The last two variables are expected to control differences in socio-economic conditions between the two sample systems.

It should be reiterated that our measure of technical inefficiency, $\mathrm{u}_{i}$, is obtained after controlling not only conventional inputs but also other variables that affect the productivity of individual rice farmers. Among the non-input exogenous variables, the location is the only variable that is related to water availability, and no other variable that measures water availability or the performance of IA is included in the regression. We are interested in observing how the distribution of farmers' technical efficiency is different between the sample systems with and without 
an IA. It is expected that, other things being equal, higher water availability and more equitable water distribution make individual farmers' productive efficiency higher and thereby more homogenous.

\section{3) Results of the estimation}

We begin the maximum likelihood estimation for the parameters of the stochastic frontier production function with the full variables in Equation (2), and delete the variables which do not contribute to improving the statistical performance of the estimation for both Mindoro and Cavite cases. As for functional forms, the Cobb-Douglas specification is statistically accepted rather than the trans-log specification for the Cavite System. Though the trans-log specification is not rejected for the Mindoro System, RESET (Regression Specification Error Test) reveals no specification error for the Cobb-Douglas form. We therefore adopt the Cobb-Douglas form for the Mindoro System too, in order to maintain comparability in estimated results between the two sample systems.

The final results of the estimation are summarized in Table 7. For the purpose of comparison, the results of the average production function estimated by applying the ordinary least squares are also shown in the table.

It is clear that the average production function and the frontier production function share nearly the same production structure in each sample system, except that the larger intercept term for the latter function exhibits a parallel upward shift of the average function to the production frontier. It is also clear that in each system the two alternative models for the frontier function yield essentially the same results, though the half-normal model gives slightly better results for both systems than the exponential model in terms of the value of log likelihood. The estimated regression coefficients are quite stable across the two alternative distributions assumed for $\mathrm{u}_{i}$. Therefore, we do not distinguish in the following the results between the two models, unless it is necessary.

Among the conventional inputs, capital gives significant coefficients with the expected sign only for the frontier functions in the Mindoro system. ${ }^{22}$ All the estimated coefficients of the remainder of the conventional inputs, land, current input and labor, have the expected sign and are statistically significant in both systems. It should be noted that the magnitudes of estimated production elasticities of these three inputs in Mindoro are comparable to the magnitudes of respective factor shares shown in Table 5. Needless to say, the production elasticities are equivalent to the functional shares of respective factor inputs under the assumption of competitive market equilibria. The close affinity between the production elasticities and the factor shares suggests that rice farmers in Mindoro are operating under competitive market conditions. In contrast, the estimated coefficients of conventional inputs in Cavite do not match the respective factor shares, suggesting that rice farmers in Cavite face certain disequilibria in the factor markets. As explained later, such disequilibria would have arisen because of the proximity of the Cavite System to Metropolitan Manila. ${ }^{13)}$

Among the variables other than the conventional inputs, the educational level of farm operators, land tenure arrangement and cropping season do not affect the productivity of rice farming in either system, and are therefore excluded from the estimation. In Mindoro it is found that the ratio of the number of farm workers to the household labor force gives a significant, positive impact on rice production, while in Cavite it is found that the age of farm operators and the ratio of rice income to the total household income have significant impacts on productivity-a negative impact in the case of age and a positive impact in the case of rice income ratio. Such results seem to indicate that growing urbanization in Cavite has adversely impacted rice farming. On the one hand, as urbanization progresses, non-farm employment opportunities at higher wage rates (see Table 3 ) attract not only family members but also the farm operators themselves out of rice farming (Dayton-Johnson [9]). On the other hand, growing demand for land in the urban land market pushes up the price of farmland. ${ }^{14)}$ The combined result is that many elderly farm operators hold paddy fields not as production assets but as assets for speculation. Such situations surrounding the labor and land markets in Cavite would have brought in the disequilibria in these markets. It should also be recalled that such growing 
Table 7. Regression results of frontier Cobb-Douglas production function, Mindoro and Cavite, 1999/2000a)

\begin{tabular}{|c|c|c|c|c|c|c|}
\hline \multirow{3}{*}{ Variable $^{b)}$} & \multicolumn{3}{|c|}{ Mindoro System $(n=123)$} & \multicolumn{3}{|c|}{ Cavite System $(n=138)$} \\
\hline & \multirow{2}{*}{$\begin{array}{l}\text { Average } \\
\text { function }\end{array}$} & \multicolumn{2}{|c|}{ Frontier function } & \multirow{2}{*}{$\begin{array}{l}\text { Average } \\
\text { function }\end{array}$} & \multicolumn{2}{|c|}{ Frontier function } \\
\hline & & Half-normal & Exponential & & Half-normal & Exponential \\
\hline \multirow[t]{2}{*}{ Land } & $0.400^{* * *}$ & $0.395^{* * *}$ & $0.371^{* * *}$ & $0.490^{* * *}$ & $0.515^{* * *}$ & $0.514^{* * *}$ \\
\hline & $(4.488)$ & $(5.447)$ & $(5.280)$ & $(5.440)$ & $(6.394)$ & $(6.182)$ \\
\hline \multirow[t]{2}{*}{ Current } & $0.191^{* * *}$ & $0.124^{* *}$ & $0.147^{* *}$ & $0.310^{* * *}$ & $0.284^{* * *}$ & $0.291^{* * *}$ \\
\hline & $(2.713)$ & $(2.055)$ & $(2.348)$ & $(3.661)$ & $(3.344)$ & $(3.582)$ \\
\hline \multirow[t]{2}{*}{ Labor } & $0.275^{* * *}$ & $0.303^{* * *}$ & $0.312^{* * *}$ & $0.254^{* *}$ & $0.228^{* *}$ & $0.221^{* *}$ \\
\hline & $(3.476)$ & $(4.428)$ & $(4.507)$ & $(2.453)$ & $(2.393)$ & $(2.131)$ \\
\hline \multirow[t]{2}{*}{ Capital } & 0.076 & $0.115^{* *}$ & $0.114^{* *}$ & 0.008 & 0.0005 & -0.006 \\
\hline & (1. 329) & $(2.117)$ & $(2.212)$ & $(0.104)$ & $(0.006)$ & $(-0.083)$ \\
\hline \multirow[t]{2}{*}{ Location } & $-0.147^{* * *}$ & $-0.132^{* * *}$ & $-0.131^{* * *}$ & $-0.062^{* *}$ & $-0.050^{*}$ & $-0.055^{* *}$ \\
\hline & $(-5.779)$ & $(-6.092)$ & $(-6.236)$ & $(-2.243)$ & $(-1.752)$ & $(-2.059)$ \\
\hline \multirow[t]{2}{*}{ Age } & 0.002 & 0.002 & 0.002 & $-0.005^{* * *}$ & $-0.005^{* * *}$ & $-0.005^{* *}$ \\
\hline & $(0.866)$ & (1. 082) & $(1.059)$ & $(-2.764)$ & $(-2.619)$ & $(-2.608)$ \\
\hline \multirow[t]{2}{*}{ Rice ratio } & -0.031 & -0.047 & -0.062 & $0.373^{* * *}$ & $0.264^{* *}$ & $0.302^{* * *}$ \\
\hline & $(-0.386)$ & $(-0.620)$ & $(-0.861)$ & (3. 647) & $(2.470)$ & $(2.670)$ \\
\hline \multirow[t]{2}{*}{ Farm woker ratio } & $0.630^{* * *}$ & $0.615^{* * *}$ & $0.627^{* * *}$ & -0.095 & 0.010 & -0.056 \\
\hline & $(3.640)$ & (3. 919) & (4. 247) & $(-0.493)$ & $(0.059)$ & $(-0.312)$ \\
\hline \multirow[t]{2}{*}{ Constant } & 5. $050 * * *$ & 5. $445^{* * *}$ & 5. $142^{* * *}$ & 4. $616^{* * *}$ & 5. $275^{* * *}$ & 5. $202^{* * *}$ \\
\hline & $(7.650)$ & (9.729) & $(9.476)$ & $(5.926)$ & $(7.758)$ & $(6.605)$ \\
\hline \multirow[t]{2}{*}{$\sigma=\left(\sigma_{\nu}^{2}+\sigma_{\omega}^{2}\right)^{1 / 2}$} & & $0.314^{* * *}$ & & & $0.401^{* * *}$ & \\
\hline & & $(9.624)$ & & & $(8.909)$ & \\
\hline$\sigma_{u}$ & & 0.298 & 0.160 & & 0.375 & 0.187 \\
\hline \multirow[t]{2}{*}{$\sigma_{v}$} & & 0.098 & $0.135^{* * *}$ & & 0.142 & $0.195^{* * *}$ \\
\hline & & & $(4.689)$ & & & $(4.624)$ \\
\hline \multirow[t]{2}{*}{$\lambda=\sigma_{v} / \sigma_{\omega}$} & & 3. $054^{* * *}$ & & & 2. $641^{* *}$ & \\
\hline & & (2.681) & & & $(2.522)$ & \\
\hline \multirow[t]{2}{*}{$\theta=1 / \mathrm{E}\left(\varepsilon_{i}\right)$} & & & $6.234^{* * *}$ & & & 5. $344^{* * *}$ \\
\hline & & & (4. 279) & & & $(2.967)$ \\
\hline Adjusted $\mathrm{R}^{2}$ & 0.888 & & & 0.746 & & \\
\hline Log likelihood & & 25.75 & 24.03 & & -9.25 & -10.66 \\
\hline
\end{tabular}

a) Coefficients with ${ }^{* * *},{ }^{* *}$ and ${ }^{*}$ are significant at $1 \%, 5 \%$ and $10 \%$, respectively. Figures in parentheses are $t$-ratios. b) The mean and standard deviation of variables included in regression analysis are presented in Tables 3 and 6 .

urbanization brings heterogeneity in various aspects into hitherto homogeneous rural communities. In Mindoro where the impact of urbanization is little felt, the strength of the labor force in farm households has a positive link to farm productivity.

The variable of importance in the context of this study is the location of paddy fields in the systems, the coefficient of which turns out to be significant both in Mindoro and Cavite. ${ }^{15)}$ The productivity of rice farming lessens as one progresses from the head-end to the tail-end of the systems. As expected from the differences in rice yield per hectare (Table 4), this pattern is particularly distinct in Mindoro, but even in Cavite where the differences in yield per hectare are not so pronounced, significant productivity differences among different locations emerge once input levels are controlled. These results lead us to conclude that the IA of the Mindoro System is not effective in reducing inequitable water 
Table 8. Statistical tests for hypotheses on the production structure and productivity impact of the irrigators' association (IA) a)

\begin{tabular}{|c|c|c|c|c|c|}
\hline & Null hypothesis & Sample & Test & Value & $\begin{array}{l}\text { Degree of } \\
\text { freedom }\end{array}$ \\
\hline (1) & $\begin{array}{l}\text { Equality of rice production structure between Mindoro } \\
\text { and Cavite }{ }^{\text {b) }}\end{array}$ & Pooled & $\begin{array}{l}\text { Likeli- } \\
\text { hood } \\
\text { ratio }\end{array}$ & $37.04^{* * *}$ & (9) \\
\hline (2) & Positive impact of IA in Mindoro on productivityc) & Pooled & $t$ & 0.144 & $(243)$ \\
\hline$(3)$ & $\begin{array}{l}\text { Equality of the coefficients of conventional inputs } \\
\text { between Mindoro and Cavite }{ }^{\mathrm{d})}\end{array}$ & Pooled & $\begin{array}{l}\text { Likeli- } \\
\text { hood } \\
\text { ratio }\end{array}$ & 6.797 & $(4)$ \\
\hline (4) & $\begin{array}{l}\text { Equality in TE between farmers who paid irrigation fees } \\
\text { and those who did not }\end{array}$ & Mindoro & $t$ & 0.711 & $(119)$ \\
\hline$(5)$ & $\begin{array}{l}\text { Equality in TE between farmers who paid irrigation fees } \\
\text { and those who did not }\end{array}$ & Cavite & $t$ & 1. $666^{*}$ & $(119)$ \\
\hline (6) & $\begin{array}{l}\text { Equality in TE (estimated using the water sufficiency } \\
\text { dummy instead of Location) between farmers who } \\
\text { paid irrigation fees and those who did note) }\end{array}$ & Cavite & $t$ & 1. 393 & $(119)$ \\
\hline
\end{tabular}

a) The FPF with half-normal distribution is used for the statistical tests. The use of FPF with exponential distribution gives essentially the same results. Values with ${ }^{* * *},{ }^{* *}$ and ${ }^{*}$ are significant at $1 \%, 5 \%$ and $10 \%$, respectively. b) Equality between Mindoro and Cavite of the slope coefficients as well as in the intercept term. c) T-value of the intercept dummy for the sample systems (Mindoro=1) allowing differences in the slope coefficients as well as the intercept term between Mindoro and Cavite. d) Equality between Mindoro and Cavite of the slope coefficients of conventional inputs. e) The same test as (5), except that TE is obtained from the FPF that is estimated with the water sufficiency dummy, instead of location.

distribution among the different locations in the system. While one can argue that the inequality in water allocation would have been even more serious had there been no IA, the degree of the negative impact of the location and the extremely high significance level of these estimates in Mindoro, as compared to those in Cavite, weaken the basis of such an argument.

An attempt to estimate a production function by pooling the data for the two sample systems reveals that the null hypothesis that there is no structural difference in rice farming between Mindoro and Cavite is rejected at the one percent significance level (the first test in Table 8). ${ }^{16)}$ More importantly in the context of this study, the pooled regression, adjusted for the structural differences between the two systems, reveals that the dummy variable setting 1 for the Mindoro System gives no significant coefficient at all (the second test in Table 8). This indicates that there is no productivity difference between the two sample systems, once differences in input levels and locations in the systems are accounted for.
One may argue that farmers in Mindoro use more inputs compared to farmers in Cavite because of assured water supply resulting from IA activities in the system, and that the production function estimation cannot capture this positive impact of the IA. Counter evidence to this argument is provided by the result of an F-test, the null hypothesis of which is that there is no significant difference between the two systems in the production structure as assumed by the production elasticities of conventional inputs (the third test in Table 8). If IA activities do indeed influence the levels of inputs, the estimated production elasticities would be different between the two sample systems. The acceptance of this null hypothesis indicates that this is not the case. All this seems to support the hypothesis that the IA in the Mindoro System fails, on average, to reveal a positive impact on the productivity of rice farming over the level attained in the Cavite System without an IA.

The estimated parameters related to the residual distributions are all statistically significant. This means that the technical ineffi- 
Table 9. Mean and variance of farmers' technical inefficiency, Mindoro and Cavite, 1999/2000

\begin{tabular}{lccc}
\hline & Mindoro & Cavite & Test value $^{\text {a) }}$ \\
\hline Half-normal distribution : & & & \\
$\quad$ Mean & 0.797 & 0.753 & $2.81^{* * *}$ \\
$\quad$ Variance & 0.014 & 0.018 & $1.27^{*}$ \\
Max. & 0.968 & 0.945 & \\
Min. & 0.515 & 0.412 & \\
Range (Max-Min) & 0.453 & 0.533 & \\
& & & \\
Exponential distribution : & & & \\
Mean & 0.857 & 0.836 & $1.82^{* *}$ \\
Variance & 0.009 & 0.010 & 1.10 \\
Max. & 0.964 & 0.947 & \\
Min. & 0.577 & 0.498 & \\
Range (Max-Min) & 0.386 & 0.449 & \\
\hline
\end{tabular}

a) T-values are reported for the test of mean equality between Mindoro and Cavite, and F-values for variance equality. The degree of freedom is 259 for the mean equality test and $(122,137)$ for the variance equality test. Values with $^{* * *},{ }^{* *}$ and ${ }^{*}$ are significant at $1 \%, 5 \%$ and $10 \%$, respectively.

ciency is statistically significant both in Mindoro and in Cavite. ${ }^{17)}$ The mean and the variance of the technical efficiency (TE) of individual farmers, estimated from the FPFs, are presented in Table 9. The half-normal model gives mean level of farmers' TE of 0.80 and 0.75 for Mindoro and Cavite, respectively. The TE of 0.80 means that the average farmer's production function is located $20 \%$ below the FPF. The exponential model gives higher means for TE : 0.86 for Mindoro and 0.84 for Cavite. ${ }^{18)}$

Comparing the two systems, the level of TE of farmers in Mindoro is significantly higher than in Cavite. Moreover, the variance in farmers' TE tends to be smaller in Mindoro than in Cavite; the null hypothesis that the variance in farmers' TE is the same between the two sample systems is rejected at the ten percent level for the half-normal model. In other words, the range of farmers' TE is narrower in Mindoro than in Cavite. Altogether, the results of the FPF estimation give a support, though weak, to the hypothesis that not only do farmers in the Mindoro System have higher TE, but they are also relatively more homogeneous in terms of their level of farming technology. In contrast, farmers in Cavite are more heterogeneous, with farmers using diverse levels of farming technology.

\section{4) Technical efficiency and irrigators' as- sociation}

In this subsection, we ask whether it is possible to deduce that the existence of the IA in the Mindoro System, by ensuring more equitable distribution of water among IA members, resulted in the high level of $\mathrm{TE}$ with small variations among farmers; and whether the Cavite System, without an IA, represents the opposite case. In the estimation of the production function, the location of farmers' paddy fields in the systems is included as the sole water-related variable, along with other variables that would possibly explain the level of TE of individual farmers, such as age and education. Suppose that the IA makes more equitable water distribution possible among farmers within each location, so that IA members can use greater volume of water at more adequate timing than otherwise. Such effects, if any, would make the technical efficiency of individual farmers higher and less variable than otherwise.

Whether this is the case for the Mindoro System could be ascertained, at least partially, by examining how the TE of individual farmers is associated with some variables related to water availability. As shown in Table 3 , we have data on the rate of irriga- 
tion fee payments. This variable cannot be an argument of the production function, but it is certainly related to water availability. The null hypothesis that there is no difference in TE between farmers who paid irrigation fees and those who did not, is accepted for Mindoro, though only at the ten percent significance level, but rejected for Cavite (the fourth and the fifth tests in Table 8). In the case of Mindoro, once the difference in location is accounted for, there is no difference in TE between payers and non-payers, which suggests that there is no variation in water availability within each location. By contrast, in the case of Cavite, TE is significantly higher for farmers who paid irrigation fees than for those who did not. This implies that inequitable water distribution exists within each location, affecting farmers' willingness to pay irrigation fees.

This point for Cavite can be further confirmed by conducting the same test for TE obtained from the FPF by substituting Location in Equation (2) for a dummy variable indicating whether farmers have sufficient water (Table 3). As this is based on a subjective evaluation by farmers as to the availability of water at their fields, it is not an ideal variable to include in the estimation of the production function. However, it can be used to examine whether water distribution is equitable within each location. With this set of TE, the statistical test cannot reject the hypothesis at the ten percent level that there is no difference in TE between farmers who paid irrigation fees and those who did not (the sixth test in Table 8). Taking the difference in water availability among individual farmers into account, farmers' TE in Cavite thus tends to become less heterogeneous, as in Mindoro.

None of these findings are inconsistent with the hypothesis that the IA of the Mindoro System plays a critical role in distributing water equitably within each location in the system. This hypothesis can be paraphrased into another hypothesis that states that the difference in technical efficiency due to uneven water distribution within each location in the Cavite System could be evened out if an effective IA were established. We failed to provide any additional evidence to support the argument that the IA in Mindoro contributes to bringing about higher technical efficiency than in Cavite. We can conjecture, however, that the IA would have contributed to higher technical efficiency by enhancing more equitable water distribution within each location in the system.

Finally, it should be mentioned that the results of the TE estimation suggest that a basic factor underlies the success of IA formation. As mentioned repeatedly, rice farming in the Cavite System displays various adverse effects of growing urbanization, such as increases in part-time farming and speculative holding of farm land. The heterogeneity in the rural community brought about by a high degree of exposure and ready access to market opportunities outside agriculture is a major hindrance in organizing farmers into an IA in order to manage their irrigation system through farmers' collective actions (Bardhan [3], Dayton-Johnson [9], Fujiie et al. [11]). The large variation in farmers' TE in Cavite is another symptom of the heterogeneity of the farming community in this system. By contrast, the small variation in farmers' TE in Mindoro indicates that farmers in this system are relatively homogeneous in terms of farming skill, reflecting the relative homogeneity of their community. Though the endogeneity problem exists in this respect, it is reasonable to infer that the difference in the characteristics of farming community between the two sample systems is a major reason for the successful establishment of an IA in Mindoro, and the failure to do so in Cavite.

\section{Concluding Remarks}

We examined the effect of irrigators' associations on the productivity of rice farming, using data obtained from two irrigation systems in the Philippines, one with an IA and the other without. The estimation of the production function confirms that the availability of irrigation water is a critical determinant of the productivity of rice farming. In the system with the IA, significant differences remain in water availability among the different locations, and on average there is no productivity difference between the system with the IA and the system without an IA. As far as this sample system is concerned, the IA is not effective in reducing in- 
equitable water distribution among the different locations in the system, and fails to demonstrate that it provides any significant advantages over the system without an IA in terms of productivity.

We found, however, that the mean level of farmers' technical efficiency is significantly higher. We also found partial evidence that the variation in farmers' technical efficiency is lower in the system with the IA than in the system without an IA. These results are consistent with the hypothesis that the IA is effective in ensuring the efficient and equitable distribution of water among farmers within each location in the system. In addition, our study singles out the heterogeneity of the rural community as a basic factor that hinders the development of an IA.

Our study thus partially rejects and partially supports the hypothesis that the existence of an IA enhances the productivity of rice farming. Needless to say, these conclusions are specific to the two sample irrigation systems studied. A more general contribution of our study is that it has presented a possible method of assessing the performance of IAs, which is usually difficult to quantify. To gain widespread support for the participatory irrigation management that is the inexorable direction for the irrigation sector not only of the Philippines but also of many developing countries in the world, the potential of IAs in improving the performance of irrigation systems must be demonstrated more widely, and the factors that determine the success or failure of the establishment of such institutions must be studied further.

1) NIA is a financially autonomous government corporation responsible for construction, rehabilitation, operation and maintenance of irrigation systems in the Philippines.

2) NIA is primarily responsible for the operation and maintenance of NISs, while CISs are operated and maintained by farmers.

3) It was irrigation development, begun in the 1950s and culminated during the decade after the world food crisis in 1973-74, that paved the way on which the green-revolution technology in rice was successfully introduced (Barker and Herdt [4], Kikuchi et al. [18]).

4) As explained earlier, a major reason for adopting PIM was said to be that the involvement of beneficiaries was a prerequisite to manage irrigation systems, which are endowed with local commons nature, satisfactorily (Bagadion [2], Mejia [22]). The other side of the coin was that the dwindling financial resources of NIA, resulting from the shying away of foreign aid from the irrigation sector under the low price regime in the international rice market, compelled NIA to hand over the maintenance responsibility to IAs as an efficient way to save government resources (Kikuchi et al. [16]).

5) There are three types of operation and maintenance (O \& M) contracts ; 1) maintenance contract, 2) irrigation fee collection contract and 3) irrigation management transfer contract. About $80 \%$ of IAs with O \& M contracts are of either type 1 or type 1) + type 2), $10 \%$ are of type 2) alone, and $10 \%$ are of type 3 ).

6) This contrasts with flat-plane dominating Region 3 (Central Luzon) where there are 17 NISs with an average area of 10,000 ha.

7) The performance level of IAs is evaluated by inspecting whether or not IAs successfully implement (a) collective work for cleaning canals and laterals, (b) coordination in rice cropping schedules, (c) practice of water rotation, and (d) organized monitoring on cropping schedule and/or water rotation. For details, see Fujiie et al. [11].

8) This IA of the Mindoro System is one of the top-ranked IAs in Table 2, with $\mathrm{O} \& \mathrm{M}$ contracts of type 1) +2 ). However, as we will see in sub-sequent sections, the water rotation in this system is not sufficient to ensure equitable water distribution among different locations of the system.

9) It should be mentioned that though off Luzon, Mindoro shares many similar characteristics in natural conditions, climatic as well as topographical, with other Region 4 provinces on Luzon, including Cavite. As such, natural conditions surrounding the two sample systems are largely comparable, though each irrigation system is certainly with own specifications.

10) It seems anomalous to see that the rate of irrigation fee collection is higher in Cavite without an IA than in Mindoro with an IA. It is the rate for Cavite System that is unusually high. As a top-rated IA, the rate for Mindoro is high as compared to the regional average of about $40 \%$. The high collection rate for Cavite may partly be explained by the presence in the system of an NIA Water Tender who is extremely enduring and enthusiastic in fee collection.

11) The imputation for the capital services derived from owned carabao/tractor is made by using the respective market rental rate. 
12) Following Greene [13 ; pp. 890-891], we adopt the significance level of $10 \%$ for conducting statistical tests, in addition to $5 \%$ and $1 \%$.

13) The issue of allocative efficiency is of great interest in this connection, but it is not addressed in this paper since the main target of our research is to ascertain IAs' impacts on productivity through examining farmers' technical efficiency.

14) It is conspicuous within the command area of the Cavite System that there are many factory lots and urban subdivisions converted from farmland.

15) It should be recalled that the location variable is a discrete variable assigning 1,2 and 3 to upper, middle and lower reaches, respectively. Instead, the locations can be taken into regression as ordinary 0-1 dummy variables, the use of which does not alter the estimation results essentially. For convenience, we present in Table 7 the results using the discrete location variable.

16) This is the reason why we did not present the results of pooled regression in Table 7.

17) One may be interested in what type of farming techniques the farmers on the frontier adopt. As observed in Section II-C, techniques adopted by rice farmers in our study areas from land preparation (by hand tractor), transplanting (manual planting) to harvesting (by sickle) and threshing (by portable threshing machine), are all the same among farmers. Differences in technical efficiency therefore arise from the ways farmers use these techniques, such as a better method of applying fertilizers.

18) The TE level in Mindoro is comparable to a TE level of 0.89 estimated for rice farmers in Nueva Ecija (Dawson et al. [8]). Many previous studies give lower TE levels for rice farmers than that of the farmers in Cavite (Thiam et al. [30]). Gonzales et al. [12] is such an example, giving the TE of rice farmers in irrigated areas in the Philippines ranging from 0.67 to 0.75 .

\section{References}

[1] Aigner, D., K. Lovell, and P. Schmidt. "Formulation and Estimation of Stochastic Frontier Production Models, "Journal of Econometrics, Vol. 6, 1977, pp. 21-37.

[2] Bagadion, B. U. "The Evolution of the Policy Context: A Historical Overview, " in F. F. Korten and R. Y.Siy, Jr., eds., Transforming a Bureaucracy: The Experience of the Philippine National Irrigation Administration. West Hartford, CT : Kumarian Press, 1988, pp. 1-19.

[3] Bardan, P. "Irrigation and Cooperation : An
Empirical Analysis of 48 Irrigation Communities in South India," Economic Development and Cultural Change, Vol. 48, 2000, pp. 847-865.

[4] Barker, R. and R. W. Herdt with B. Rose. The Rice Economy of Asia, Washington, D. C.: Resources for the Future, 1985.

[5] Battese, G. E. and T. J. Coelli. “A Model for Productive Inefficiency Effects in a Stochastic Frontier Production Function for Panel Data," Empirical Economics, Vol.20, 1995, pp. 325332 .

[6] Bureau of Agricultural Statistics. Crop Statistics, BAS homepage, (www. bas. gov.ph/), 2004.

[7] Chambers, R. Managing Canal Irrigation. New Delhi : Oxford and IBH Publishing Co., 1988.

[8] Dawson, P. J., J. Lingard, and C. H. Woodford. "A Generalized Measure of Farm-Specific Technical Efficiency," American Journal of Agricultural Economics, Vol.73, 1991, pp.10981104 .

[9] Dayton-Johnson, J. “Determinants of Collective Action on the Local Commons : A Model with Evidence from Mexico," Journal of Development Economics, Vol.62, 2000, pp. 181-208.

[10] Farrell, M. J. "The Measurement of Productive Efficiency," Journal of the Royal Statistical Society, Series A (General), Vol. 120, 1957, pp. 253-281.

[11] Fujiie, M., M. Kikuchi, and Y. Hayami. "The Conditions for Collective Action for Local Commons Management: The Case of Irrigation in the Philippines," Agricultural Economics, forthcoming.

[12] Gonzales, L. A., L. S. Sebastian, E. D. Redona, V. A. Gonzales, C. D. Elca, G. F. Lapina, F. C. Hidalgo, A. B. Mataia, P. A. Alviola, and S. J. Banta. Technical and Allocative Efficiencies of Philippine Rice Production. Manila: STRIVE Foundation and Philippine Rice Research Institute, 2004.

[13] Greene, W.H. Econometric Analysis (5th Ed.). Upper Saddle River, NJ : Prentice Hall, 2003.

[14] Kalirajan, K.P. "On Measuring Economic Efficiency," Journal of Applied Econometrics, Vol. 12, 1990, pp. 233-238.

[15] Kikuchi, M., G. Dozina, Jr., and Y. Hayami. "Economics of Community Work Programs : A Communal Irrigation Project in the Philippines," Economic Development and Cultural Change, Vol. 26, 1978, pp. 211-225.

[16] Kikuchi, M., M. Fujita, and Y. Hayami. "State, Community and Market in the Deterioration of an Irrigation System in the Philippines," in M. Aoki and Y. Hayami eds., Communities and Markets in Economic Develop- 
ment. Oxford and New York : Oxford University Press, 2001, pp. 265-294.

[17] Kikuchi, M., A. Maruyama, and Y. Hayami. "Investment Inducements to Public Infrastructure: Irrigation in the Philippines and Sri Lanka since Independence," FASID Discussion Paper, No. 2002-003, Tokyo : FACID, 2002.

[18] Kikuchi, M., A. Maruyama, and Y.Hayami. "Phases of Irrigation Development in Asian Tropics: A Case Study of the Philippines and Sri Lanka," Journal of Development Studies, Vol. 39, 2003, pp. 109-138.

[19] Kloezen, W. H., C. Garces-Restrepo, and S. H. Johnson III. "Impact Assessment of Irrigation Management Transfer in the Alto Rio Lerma Irrigation District, Mexico," Research Report 15, Colombo: International Irrigation Management Institute, 1997.

[20] Korten, F.F. and R. Y.Siy, eds. Transforming a Bureaucracy: The Experience of the Philippine National Irrigation Administration. West Hartford : CT, Kumarian Press, 1988.

[21] Masicat, P., M. V. de Vega, and P. L. Pingali. "Philippine Irrigation Infrastructure : Degradation Trends for Luzon 1966-1989, " IRRI Social Science Division Paper, No.90-03. Los Banos: Philippines: International Rice Research Institute, 1990.

[22] Mejia, A. M. "Participatory Irrigation Management in the Philippines: Issues and Constraints, " in Organizational Change for Participatory Irrigation Management. Tokyo : Asian Productivity Organization, 2002, pp. 77-90.

[23] National Irrigation Administration. YearEnd Report to the President 2003. Quezon City : National Irrigation Administration, 2004.

[24] Oorthuizen, J. and W. H. Kloezen. "The Other Side of the Coin : A Case Study on the Impact of Financial Autonomy on Irrigation Management Performance in the Philippines," Irrigation and Drainage Systems, Vol. 9, 1995, pp. 15-37.

[25] Ostrom, E. Crafting Institution of SelfGoverning Irrigation Systems. San Francisco:
Institute for Contemporary Studies Press, 1992.

[26] Pitt, M. M. and L.F. Lee. "The Measurement and Sources of Technical Inefficiency in Indonesian Weaving Industry," Journal of Development Economics, Vol. 9, 1981, pp. 43-64.

[27] Simar, L. , C. A. K. Lovell, and P. V. Eeckaut. "Stochastic Frontiers Incorporating Exogenous Influences," a discussion paper of the Institute of Statistics, the Catholic University of Louvain, Belgium, 1994. (Available at : www. stat. ucl. ac. be / ISpublication / ISdp _ ListAnn. html\#dp1994).

[28] Small, L. E. and I. Carruthers. Farmer-Financed Irrigation: An Economics of Reform. Cambridge : Cambridge University Press, 1991.

[29] Svendsen, M. “Assessing Effects of Policy Change on Philippine Irrigation Performance." Working Paper on Irrigation Performance 2. Washington, D. C. : International Food Policy Research Institute, 1992.

[30] Thiam, A., B. E. Bravo-Ureta, and T. E. Rivas. "Technical Efficiency in Developing Country Agriculture: A Meta-Analysis," Agricultural Economics, Vol. 25, 2001, pp. 235-243.

[31] Uphoff, N. Improving Irrigation Management with Farmer Participation: Getting the Process Right. Boulder: Westview, 1986.

[32] Uphoff, N. and C. M. Wijayaratna. "Demonstrated Benefits from Social Capital : The Productivity of Farmer Organizations in Gal Oya, Sri Lanka," World Development, Vol. 28, 2000, pp. $1875-1890$.

[33] Vermillion, D. L. “Impacts of Irrigation Management Transfer: A Review of the Evidence." Research Report 11. Colombo : International Irrigation Management Institute, 1997.

[34] Wijayaratna, C. M. and D. L. Vermillion. "Irrigation Management Turnover in the Philippines : Strategy of the National Irrigation Administration." Short Report Series on Locally Managed Irrigation 4. Colombo : International Irrigation Management Institute, 1994.

(Received October 8, 2004 ; accepted December 10, 2004) 